\title{
Effects of Exercise Training under Hyperbaric Oxygen on Oxidative Stress Markers and Endurance Performance in Young Soccer Players: A Pilot Study
}

\author{
Carlos Burgos, ${ }^{1}$ Carlos Henríquez-Olguín, ${ }^{1}$ David Cristóbal Andrade, ${ }^{1}$ \\ Rodrigo Ramírez-Campillo, ${ }^{1,2}$ Oscar F. Araneda, ${ }^{3}$ Allan White, ${ }^{4}$ and Hugo Cerda-Kohler ${ }^{1,5}$ \\ ${ }^{1}$ Unidad de Fisiología Integrativa del Ejercicio, Laboratorio de Ciencias del Ejercicio, Clínica MEDS, Avenida Isabel La Católica 3740, \\ 7550557 Santiago, Chile \\ ${ }^{2}$ Departamento de Ciencias de la Actividad Física, Núcleo de Investigación en Salud, Actividad Física y Deporte, \\ Universidad de Los Lagos, Avenida Fuchslocher 1035, 5290000 Osorno, Chile \\ ${ }^{3}$ Laboratorio Integrativo de Biomecánica y Fisiología del Esfuerzo (LIBFE), Escuela de Kinesiología, Facultad de Medicina, \\ Universidad de los Andes, Avenida Monseñor Álvaro del Portillo 12455, 7620001 Santiago, Chile \\ ${ }^{4}$ Laboratorio Ciencias de la Actividad Física, Instituto de Ciencias Biomédicas, Facultad de Medicina, Universidad de Chile, \\ Avenida Independencia 1027, 8380453 Santiago, Chile \\ ${ }^{5}$ Escuela de Ciencias de la Actividad Física, el Deporte y la Salud, Facultad de Medicina, Universidad de Santiago, \\ Avenida Libertador Bernardo O’Higgins 3363, 9170022 Santiago, Chile
}

Correspondence should be addressed to Carlos Burgos; burgosmeds@yahoo.com

Received 30 July 2016; Revised 24 October 2016; Accepted 30 October 2016

Academic Editor: Phillip B. Hylemon

Copyright (c) 2016 Carlos Burgos et al. This is an open access article distributed under the Creative Commons Attribution License, which permits unrestricted use, distribution, and reproduction in any medium, provided the original work is properly cited.

The aim of the present study was to determine the effects of three weeks of hyperbaric oxygen $\left(\mathrm{HBO}_{2}\right)$ training on oxidative stress markers and endurance performance in young soccer players. Participants (18.6 \pm 1.6 years) were randomized into hyperbarichyperoxic $(\mathrm{HH})$ training $(n=6)$ and normobaric normoxic $(\mathrm{NN})$ training $(n=6)$ groups. Immediately before and after the 5th, 10th, and 15th training sessions, plasma oxidative stress markers (lipid hydroperoxides and uric acid), plasma antioxidant capacity (6-hydroxy-2,5,7,8-tetramethylchroman-2-carboxylic acid [TROLOX]), arterial blood gases, acid-base balance, bases excess (BE), and blood lactate analyses were performed. Before and after intervention, maximal oxygen uptake $\left(\mathrm{VO}_{2} \max \right)$ and peak power output (PPO) were determined. Neither $\mathrm{HH}$ nor NN experienced significant changes on oxidative stress markers or antioxidant capacity during intervention. $\mathrm{VO}_{2}$ max and $\mathrm{PPO}$ were improved (moderate effect size) after $\mathrm{HH}$ training. The results suggest that $\mathrm{HBO}_{2}$ endurance training does not increase oxidative stress markers and improves endurance performance in young soccer players. Our findings warrant future investigation to corroborate that $\mathrm{HBO}_{2}$ endurance training could be a potential training approach for highly competitive young soccer players.

\section{Introduction}

Hyperbaric oxygen $\left(\mathrm{HBO}_{2}\right)$ therapy is the medical administration of $100 \%$ oxygen $\left(\mathrm{O}_{2}\right)$ at pressures higher than 1 absolute atmosphere (ATA) and during the last decade elite and competitive athletes have used $\mathrm{HBO}_{2}$ to accelerate the recovery after injuries or exercise-induced muscle damage [13].
$\mathrm{O}_{2}$ plays an essential role in cell metabolism and its availability is a principal determinant of maximal $\mathrm{O}_{2}$ uptake $\left(\mathrm{VO}_{2} \max \right)$ [4]. Acute exposure to normobaric hyperoxia (i.e., $60 \%$ to $100 \% \mathrm{O}_{2}$ ) increases $\mathrm{O}_{2}$ availability and may improve physical performance in a dose-dependent manner $[5,6]$. However, It has been shown that preexercise exposure to normobaric hyperoxia did not modify the performance during high intensity exercise [7, 8], endurance exercise [9], 
or resistance training [7]. Similarly, preexposure to $\mathrm{HBO}_{2}$ has no acute effect on physical performance $[10,11]$. Furthermore, it has been suggested that long-term training in normobaric hyperoxia has no additional effect on endurance performance adaptations $[12,13]$. This lack of effects could be related to $\mathrm{O}_{2}$ diffusion limitation during normobaric hyperoxia exposure [14]. Therefore, other hyperoxic environments, such as $\mathrm{HBO}_{2}$, may be more suitable for long-term endurance adaptations since this condition allows a higher $\mathrm{O}_{2}$ diffusion [15].

Exposures to supraphysiological $\mathrm{O}_{2}$ levels may increase the risk of developing systemic and cellular oxidative stress [16-18]. Besides, it has been reported that $\mathrm{HBO}_{2}$ induces symptoms of central nervous system toxicity as headache or nausea in $\sim 2-6 \%$ of divers who dive between $\sim 1.3$ and 1.6 ATA with an oxygen concentration of $\sim 91 \%$. However, the probability of these symptoms to appear only increases after $4 \mathrm{~h}$ of diving $[19,20]$. Thus, it is still a matter of debate if $\mathrm{HBO}_{2}$ training may induce harmful effects as oxidative stress [7, 21].

To our knowledge, no studies have been carried out to establish the chronic effects of intermittent $\mathrm{HBO}_{2}$ training on oxidative stress and endurance performance in soccer players. The aim of this pilot study was to determine the chronic effects of endurance training under $\mathrm{HBO}_{2}$ on oxidative stress and endurance performance. It was hypothesized that $\mathrm{HBO}_{2}$ training does not increase oxidative stress biomarkers and induces greater endurance adaptations compared to normobaric hyperoxia training in young soccer players.

\section{Material and Methods}

2.1. Experimental Approach. To compare the acute and chronic effects of $\mathrm{HBO}_{2}$ versus normobaric normoxia training on oxidative stress and endurance performance, the participants were randomized into a hyperbaric hyperoxia training group $(\mathrm{HH}, n=6)$ and normobaric normoxia training group ( $\mathrm{NN}, n=6)$ during three weeks. Immediately before and after the 1st (baseline), 5th, 10th, and 15th training sessions, oxidative stress markers (plasma lipid hydroperoxides and plasma uric acid), plasma antioxidant capacity (6-hydroxy-2,5,7,8-tetramethylchroman-2-carboxylic acid [TROLOX]), arterial blood gases, acid-base balance, and lactate analysis were performed. Furthermore, before and after three weeks of training, $\mathrm{VO}_{2}$ max and peak power output (PPO) were measured with a cycle ergometer test (Figure 1).

2.2. Participants. Twelve young male soccer players (18.6 \pm 1.6 years) participating in the young Chilean National Soccer Championship were included in the pilot study. The participants were recruited from the same team; therefore, they had similar training/competition load and nutritional support. All measurements were carried out between 8:00 a.m. and 12:00 p.m. All participants were medically assessed and carefully informed about the experimental procedures and possible risks and benefits associated with participation in the study and signed an informed consent. The study was conducted in accordance to the Declaration of Helsinki and was approved by the ethics committee of the Faculty of
TABLE 1: Baseline characteristics of the study participants.

\begin{tabular}{lcc}
\hline & NN group $(n=6)$ & HH group $(n=6)$ \\
\hline Age (years) & $18.5 \pm 1.6$ & $18.8 \pm 1.6$ \\
Height $(\mathrm{cm})$ & $175.8 \pm 2.7$ & $177.5 \pm 2.3$ \\
Body mass $(\mathrm{kg})$ & $68.1 \pm 6.4$ & $71.7 \pm 2.3$ \\
Body fat mass (\%) & $14.4 \pm 4.0$ & $13.9 \pm 1.9$ \\
Body muscle mass (\%) & $43.9 \pm 2.9$ & $45.0 \pm 2.5$ \\
\hline
\end{tabular}

Data is shown as mean $\pm \mathrm{SD}$. $\mathrm{NN}=$ normobaric normoxia. $\mathrm{HH}=$ hyperbaric hyperoxia.

Medicine, Universidad de Chile. Subject characteristics are presented in Table 1 .

2.3. Training Program. All study was performed in a hyperbaric chamber at $\sim 540 \mathrm{~m}$ above sea. Additionally to their regular training, soccer players from the $\mathrm{HH}$ and $\mathrm{NN}$ groups were submitted to $30 \mathrm{~min}$ of endurance exercise on a cycle ergometer (Ergomedic 828E Monark, Sweden), at $75 \%$ of power output at $\mathrm{VO}_{2} \max$ during three weeks. The $\mathrm{NN}$ group completed 15 endurance training sessions (5 times per week) in a hyperbaric chamber (Model C.H.10 N 4 , Osorio Hnos. y Cia. Ltda., Chile) at 1 atmosphere absolute (ATA) (unpressurized chamber), breathing normoxic gas (air) $(21 \%$ $\mathrm{O}_{2}$ ). HH group completed the same volume of endurance training with an additional ATA (i.e., at 2.0 ATA) in the hyperbaric chamber breathing hyperoxic gas $\left(100 \% \mathrm{O}_{2}\right)$ (see schematic representation in Figure 1).

2.4. Cycle Ergometer Test. To determine the chronic effect of $\mathrm{HBO}_{2}$ on endurance performance $\left(\mathrm{VO}_{2} \max\right.$ and $\left.\mathrm{PPO}\right)$, each participant completed an incremental maximum cycle ergometer (Ergomedic 828E Monark, Sweden) test previously described [22] under normobaric normoxic conditions, 72 hours before and after the three-week training period. Briefly, the test started at a power output of $75 \mathrm{~W}$ and the workload was increased $25 \mathrm{~W} \cdot \mathrm{min}^{-1}$ to exhaustion. The test was finished when minimum pedal cadence could not be maintained at $70 \mathrm{rpm}$. Gas exchange was recorded continuously with a portable breath-to-breath gas analyzer (Cortex Metamax 3B, Leipzig, Germany). The analyzer was calibrated according to the manufacturer instructions prior to each trial. Pulmonary ventilation ( $\mathrm{VE}), \mathrm{O}_{2}$ uptake $\left(\mathrm{VO}_{2}\right)$, expired carbon dioxide $\left(\mathrm{VCO}_{2}\right)$, and respiratory exchange ratio (RER) were averaged over $10 \mathrm{~s}$, with the highest $30 \mathrm{~s}$ value (i.e., three consecutive $10 \mathrm{~s}$ periods) used in the analysis. $\mathrm{VO}_{2} \max$ was determined according to achievement of previously established criteria [23]: (1) plateau in oxygen consumption (increase < $\left.150 \mathrm{~mL} \cdot \mathrm{min}^{-1}\right)$, (2) respiratory exchange ratio $>1.1$, and (3) $\geq 90 \%$ of theoretical maximal heart rate. The $\mathrm{VO}_{2}$ max was expressed relative to body mass $\left(\mathrm{mL} \cdot \mathrm{kg}^{-1} \cdot \mathrm{min}^{-1}\right)$ and PPO in watts (w).

2.5. Blood Sampling. Immediately before and after the 1st (baseline), 5th, 10th, and 15th training sessions, oxidative stress markers (plasma lipid hydroperoxides and plasma 


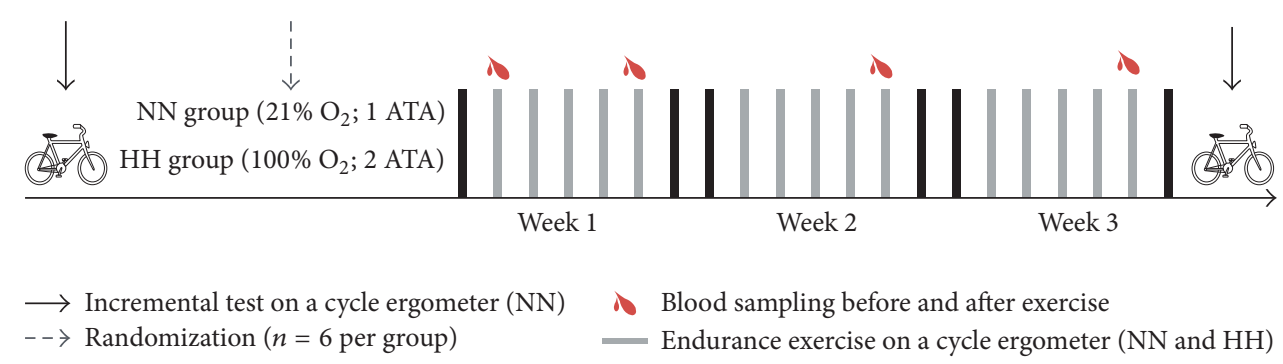

FIGURE 1: Schematic representation of training intervention. $\mathrm{NN}=$ normobaric normoxia; $\mathrm{HH}=$ hyperbaric hyperoxia. ATA $=$ absolute atmosphere.

uric acid), plasma antioxidant capacity (6-hydroxy-2,5,7,8tetramethylchroman-2-carboxylic acid [TROLOX]), arterial blood gases, and acid-base balance analyses were performed.

All plasmatic variables were analyzed from blood samples $(10 \mathrm{~mL})$ obtained from the brachial vein. Samples were centrifuged at $2.422 \times \mathrm{g}(\mathrm{RCF})$ for 10 minutes (Model PLC03, Gemmy Industrial Corp., Germany). The plasma obtained was divided into aliquots of $4 \mathrm{~mL}$ and transported to the laboratory in a container with crushed ice, where they were frozen at $-80^{\circ} \mathrm{C}$ until the time of analysis.

2.6. Plasma Lipid Hydroperoxides. For the analysis of plasma lipid hydroperoxides a routine procedure was used [24]. Briefly, $100 \mu \mathrm{L}$ of methanol with triphenylphosphine $(15 \mathrm{mM}$ - inhibitor of endoperoxides) was added to $100 \mu \mathrm{L}$ of deproteinized plasma with TCA $15 \%$ and incubated for $30 \mathrm{~min}$. Then $900 \mu \mathrm{L}$ of FOX version 2 was added and incubated during $45 \mathrm{~min}$ at room temperature. The peroxides on the sample oxidized $\mathrm{Fe}^{+2}$ to $\mathrm{Fe}^{+3}$, in an acidic medium of $\mathrm{H}_{2} \mathrm{SO}_{4}$ $(25 \mathrm{mM})$. This process was monitored with xylenol orange (i.e., it changes from yellow to blue when it reacts with $\mathrm{Fe}^{+3}$ ) and the absorbance was evaluated with a spectrophotometer (S-20 Vis, Boeco Germany) set at $560 \mathrm{~nm}$. A standard curve was constructed with $\mathrm{H}_{2} \mathrm{O}_{2}$.

2.7. Plasma Uric Acid. The used method was based upon the oxidation of uric acid to alatoine and $\mathrm{H}_{2} \mathrm{O}_{2}$ by the uricase enzyme. $\mathrm{H}_{2} \mathrm{O}_{2}$ reacts with 3-5-dichloro-2-hydroxybencesulfonic and 4-aminoantipyrine by the peroxidase (Valtek Diagnostics, Santiago, Chile). Briefly, $1.0 \mathrm{~mL}$ of uricase and peroxidase was added to $25 \mu \mathrm{L}$ of plasma and uric acid $(10 \mathrm{mg} / \mathrm{dL})$. Then, the solution was stirred vigorously and incubated for $5 \mathrm{~min}$ at $37^{\circ} \mathrm{C}$. The absorbance of the sample at $520 \mathrm{~nm}$ was evaluated using a spectrophotometer (S-20 Vis, Boeco Germany).

2.8. Plasma Antioxidant Capacity. Plasma antioxidant capacity was determined with a 1250 Luminometer (LKB-Wallac, Turku, Finland) and according to previously described methods $[25,26]$. Briefly, using the chemiluminescence technique to measure the antioxidant capacity of biological fluids, the light emission occurs when the chemiluminescent substrate (i.e., luminol) is oxidized by $\mathrm{H}_{2} \mathrm{O}_{2}$ in a reaction catalyzed by "horseradish peroxidase." The stabilities and intensities of the light emitted are high due to the addition of p-iodine phenol. Its emission depends on the constant production of intermediate free radicals derivative of p-iodine phenol, luminal, and $\mathrm{O}_{2}$. For this reason, the light emission is sensitive for antioxidants but is reestablished when these antioxidants are consumed in the reaction. As the generation of intermediate free radicals is constant, the light suppression period is directly related to the amount of antioxidant in the sample. The assessment is sensitive enough to measure the antioxidant capacity of biological samples, being expressed relatively to the TROLOX, soluble analogous of the vitamin E. The plasma antioxidant capacity results are expressed as an equivalent of TROLOX per liter of sample $(\mu \mathrm{mol} / \mathrm{L})$.

2.9. Blood Lactate. For lactate measurements, capillary blood was obtained from earlobe and assessed with reagent strips (BM-Lactate, Roche Diagnostics, Germany) [27] and a portable handheld lactate meter (Accusport ${ }^{\circledR}$, Boehringer Mannheim, Germany).

2.10. Blood Gases and Acid-Base Analysis. Plasmatic variables were analyzed from blood samples obtained from the brachial vein. $\mathrm{O}_{2}$ partial pressure $\left(\mathrm{PO}_{2}\right)$, bicarbonate $\left(\mathrm{HCO}_{3}{ }^{-}\right)$, base excess $(\mathrm{BE})$, carbon dioxide partial pressure $\left(\mathrm{PCO}_{2}\right)$, and $\mathrm{pH}$ were determined using a portable gas analyzer (i-STAT, Abbot Lab. USA). All the results were normalized to body temperature. $\mathrm{HCO}_{3}{ }^{-}$and $\mathrm{BE}$ were determined in relation to $\mathrm{pH}$ and $\mathrm{PCO}_{2}$ by the Henderson-Hasselbalch equation. The $\mathrm{PO}_{2}$ was determined through oxidation current, which is proportional to $\mathrm{O}_{2}$ dissolved in blood.

2.11. Statistical Analysis. Descriptive statistics (mean \pm SD) for the different variables were calculated. Shapiro-Wilk normality test for the dependent variables data was used to determine if the distribution was normal. According to results shown by Impellizzeri et al. [28], the sample size $(n=6$ per group) allows identification of a difference of $5.4 \mathrm{~mL} \cdot \mathrm{kg}^{-1} \cdot \mathrm{min}^{-1}$ in $\mathrm{VO}_{2}$ max between groups, assuming a statistical power of $80 \%$.

The practical significance of data was assessed via magnitude-based inferences [29]. Because the formula for Cohen's $d$ gives a biased estimate of the population effect size, especially for small samples ( $n<20)$, effect sizes (ES, 90\% CI) were calculated through the corrected effect size, or Hedges's 
TABLE 2: Plasma oxidative stress markers and antioxidant capacity immediately before (pre) and after (post) the 5th, 10th, and 15th training session during 3 weeks of hyperbaric hyperoxia $(\mathrm{HH})$ and normobaric normoxia $(\mathrm{NN})$ endurance training.

\begin{tabular}{lccccccc}
\hline & & Baseline & 5th session & 10th session & 15th session & Pre-post ES $(90 \%$ CI $)$ & Rating \\
\hline NN & & & & & & \\
Plasma uric acid $(\mathrm{mg} / \mathrm{dL})$ & Pre & $4.5 \pm 0.2$ & $6.8 \pm 3.4$ & $5.7 \pm 3.2$ & $5.9 \pm 3.4$ & $0.5(-0.4 / 1.5)$ & Unclear \\
& Post & $5.0 \pm 0.7$ & $6.4 \pm 3.7$ & $5.1 \pm 2.3$ & $5.8 \pm 1.8$ & $0.5(-0.5 / 1.5)$ & Unclear \\
Plasma lipid hydroperoxides $(\mu \mathrm{mol} / \mathrm{L})$ & Pre & $6.2 \pm 2.3$ & $7.3 \pm 3.5$ & $8.7 \pm 5.1$ & $6.5 \pm 4.7$ & $0.1(-0.9 / 1.0)$ & Unclear \\
& Post & $9.1 \pm 4.7$ & $8.2 \pm 4.5$ & $10.3 \pm 3.9$ & $8.5 \pm 4.7$ & $-0.1(-1.1 / 0.8)$ & Unclear \\
& Pre & $207 \pm 76.9$ & $222 \pm 112$ & $188 \pm 105$ & $192 \pm 113$ & $-0.1(-1.1 / 0.8)$ & Unclear \\
TROLOX $(\mu \mathrm{mol} / \mathrm{L})$ & Post & $183 \pm 83.1$ & $210 \pm 123$ & $165 \pm 75.8$ & $190 \pm 61.3$ & $0.1(-0.9 / 1.0)$ & Unclear \\
\hline HH & & & & & & \\
Plasma uric acid $(\mathrm{mg} / \mathrm{dL})$ & Pre & $6.0 \pm 1.6$ & $6.3 \pm 1.6$ & $6.3 \pm 1.7$ & $6.1 \pm 0.2$ & $0.1(-0.8 / 1.1)$ & Unclear \\
& Post & $5.7 \pm 2.0$ & $7.3 \pm 1.9$ & $6.7 \pm 1.5$ & $6.0 \pm 1.1$ & $0.2(-0.8 / 1.1)$ & Unclear \\
Plasma lipid hydroperoxides $(\mu \mathrm{mol} / \mathrm{L})$ & Pre & $5.6 \pm 3.9$ & $5.6 \pm 3.9$ & $6.4 \pm 3.7$ & $5.9 \pm 3.4$ & $0.1(-0.9 / 1.0)$ & Unclear \\
& Post & $5.4 \pm 3.3$ & $5.4 \pm 3.3$ & $6.5 \pm 3.1$ & $8.4 \pm 3.2$ & $0.9(-0.1 / 1.9)$ & Unclear \\
TROLOX $(\mu \mathrm{mol} / \mathrm{L})$ & Pre & $207 \pm 34.7$ & $205 \pm 54.1$ & $207 \pm 57.9$ & $200 \pm 9.5$ & $-0.3(-1.2 / 0.7)$ & Unclear \\
& Post & $219 \pm 18.4$ & $238 \pm 61.7$ & $219 \pm 48.7$ & $195 \pm 36.9$ & $-0.8(-1.7 / 0.2)$ & Unclear \\
\hline
\end{tabular}

Data is shown as mean \pm SD. TROLOX: plasma antioxidant capacity.

$g$ [30]. The following threshold values for ES were employed: $<0.2$ as trivial, $>0.2$ as small, $>0.6$ as moderate, $>1.2$ as large, $>2.0$ as very large, and 4.0 as extremely large [31]. Traditional statistical approach was assessed using Kruskal-Wallis test followed by Dunn's post hoc analysis and 2-way ANOVA followed by Tukey post hoc analysis. The $\alpha$ level was set at $p<0.05$ for statistical significance. All statistical analysis was performed using GraphPad Prism 6.0 (GraphPad Software, Inc., San Diego, CA, USA).

\section{Results}

Before intervention no differences were found between groups for descriptive characteristics (Table 1).

In order to clarify if chronic or acute $\mathrm{HBO}_{2}$ exercise training increases oxidative stress, plasma lipid hydroperoxides, plasma uric acid, and plasma antioxidant capacity (TROLOX) were measured once a week during the training program (see Material and Methods). No differences in oxidative stress markers were observed in $\mathrm{HH}$ and $\mathrm{NN}$ during intervention $(p>0.05$, Table 2). ES showed unclear effect in all variables either in basal or postexercise values during intervention.

To analyze changes in acid-base balance, a blood sample was obtained immediately before and after the 1st and 15th endurance training sessions (Table 3). Plasmatic $\mathrm{HCO}_{3}{ }^{-}$ $(-27 \%, p=0.001 ;-30 \%, p=0.0003$, 1st and 15 th session, resp.) and $\mathrm{BE}(-145 \%, p=0.001 ;-179 \%, p=0.0004$, 1st and 15th session, resp.) were significantly reduced after training sessions only in the NN group (Table 3). ES shows unclear effect in all variables either in pre-post basal or pre-post exercise values during intervention.

A low concentration of blood lactate in normobaric hyperoxia or $\mathrm{HBO}_{2}$ conditions has been reported in many studies $[19,20,24,26]$. Plasma lactate was significantly increased after training sessions (181\%, $p=0.0002 ; 134 \%, p=$ $0.001,1$ st and 15 th session, resp.) only in NN group (Table 3 ). Furthermore, postexercise plasma lactate was significantly higher in NN versus $\mathrm{HH}$ group after training sessions (135\%, $p=0.004 ; 162 \%, p=0.029,1$ st and 15 th session, resp.) (Table 3). ES shows unclear effect in all variables either in prepost basal or pre-post exercise values during intervention.

To determine the endurance adaptations to $\mathrm{HBO}_{2}$ training, participants performed an incremental test before and after experimental intervention. Traditional statistical approach shows no significant differences between groups in $\mathrm{VO}_{2}$ max or PPO before and after training (Figure 1). However, ES shows an unclear effect and a moderate effect in $\mathrm{VO}_{2}$ max and $\mathrm{PPO}$ for $\mathrm{NN}$ and $\mathrm{HH}$ groups, respectively.

\section{Discussion}

The main findings of the present study suggest that 3 weeks of exercise training in $\mathrm{HBO}_{2}$ condition do not increase oxidative stress markers and seem to improve endurance capacity compared to normobaric normoxia training in young soccer players.

Several diseases have been associated with oxidative stress and others with free radical production. In skeletal muscle, exercise induces an increase of mitochondrial and nonmitochondrial [32] reactive oxygen species (ROS) generation. Some studies have shown that high dietary antioxidant intake is associated with an impair in the exercise-induced adaptive gene expression [33, 34]. Thus, during the last decade ROS molecules have emerged as key players in the molecular response to exercise.

Some animal and human data have suggested that breathing supraphysiological $\mathrm{O}_{2}$ exposure may increase ROS production and induce oxidative stress $[16,17,35]$. However, the $\mathrm{HBO}_{2}$-induced DNA damage rapidly disappears after the end of the $\mathrm{HBO}_{2}$ exposure in healthy humans [36]. Moreover, DNA damage was detected only after the first treatment and not after further treatments under the same conditions, indicating an increase in antioxidant defense [36]. In the present study, we showed that acute and chronic training 
TABLe 3: Acid-base balance immediately before (pre) and after (post) training session of 3 weeks of hyperbaric hyperoxia (HH) and normobaric normoxia (NN) endurance training.

\begin{tabular}{|c|c|c|c|c|c|}
\hline & & Baseline & 15th session & Pre-post ES (90\% CI) & Rating \\
\hline \multicolumn{6}{|l|}{$\mathrm{NN}$} \\
\hline \multirow{2}{*}{$\mathrm{PCO}_{2}(\mathrm{mmHg})$} & Pre & $56.5 \pm 8.0$ & $55.5 \pm 7.2$ & $-0.1(-1.1 / 0.8)$ & Unclear \\
\hline & Post & $39.2 \pm 7.8^{*}$ & $37.3 \pm 2.1^{*}$ & $-0.3(-1.3 / 0.6)$ & Unclear \\
\hline \multirow{2}{*}{$\mathrm{PO}_{2}(\mathrm{mmHg})$} & Pre & $24.2 \pm 7.4$ & $22.0 \pm 8.2$ & $-0.3(-1.2 / 0.7)$ & Unclear \\
\hline & Post & $58.7 \pm 19.5^{*}$ & $63.0 \pm 11.4^{*}$ & $0.2(-0.7 / 1.2)$ & Unclear \\
\hline \multirow{2}{*}{$\mathrm{pH}$} & Pre & $7.32 \pm 0.04$ & $7.34 \pm 0.03$ & $0.5(-0.4 / 1.5)$ & Unclear \\
\hline & Post & $7.34 \pm 0.02$ & $7.33 \pm 0.10$ & $-0.1(-1.1 / 0.8)$ & Unclear \\
\hline \multirow{2}{*}{ Base excess $(\mathrm{mmol} / \mathrm{L})$} & Pre & $3.3 \pm 1.8$ & $3.1 \pm 1.5$ & $-0.1(-1.1 / 0.8)$ & Unclear \\
\hline & Post & $-4.8 \pm 3.1^{* \alpha}$ & $-5.6 \pm 5.1^{* \alpha}$ & $-0.2(-1.1 / 0.8)$ & Unclear \\
\hline \multirow{2}{*}{ Bicarbonate $(\mathrm{mmol} / \mathrm{L})$} & Pre & $29.3 \pm 1.9$ & $29.1 \pm 1.6$ & $-0.1(-1.1 / 0.8)$ & Unclear \\
\hline & Post & $21.3 \pm 3.3^{* \alpha}$ & $20.3 \pm 3.9^{*}$ & $-0.3(-1.2 / 0.7)$ & Unclear \\
\hline \multirow{2}{*}{ Lactate $(\mathrm{mmol} / \mathrm{L})$} & Pre & $2.1 \pm 0.2$ & $2.3 \pm 0.4$ & $0.6(-0.4 / 1.6)$ & Unclear \\
\hline & Post & $6.0 \pm 1.5^{* \alpha}$ & $5.5 \pm 1.7^{* \alpha}$ & $-0.3(-1.2 / 0.7)$ & Unclear \\
\hline \multicolumn{6}{|l|}{$\mathrm{HH}$} \\
\hline \multirow{2}{*}{$\mathrm{PCO}_{2}(\mathrm{mmHg})$} & Pre & $52.8 \pm 5.9$ & $53.1 \pm 5.7$ & $0.0(-0.9 / 1.0)$ & Unclear \\
\hline & Post & $48.7 \pm 8.6$ & $49.4 \pm 14.4$ & $0.1(-0.9 / 1.0)$ & Unclear \\
\hline \multirow{2}{*}{$\mathrm{PO}_{2}(\mathrm{mmHg})$} & Pre & $32.0 \pm 12.6$ & $24.5 \pm 10.6$ & $-0.6(-1.6 / 0.4)$ & Unclear \\
\hline & Post & $37.2 \pm 16.6$ & $31.0 \pm 16.9$ & $-0.3(-1.3 / 0.6)$ & Unclear \\
\hline \multirow{2}{*}{$\mathrm{pH}$} & Pre & $7.40 \pm 0.03$ & $7.40 \pm 0.01$ & $0.0(-0.9 / 0.9)$ & Unclear \\
\hline & Post & $7.40 \pm 0.04$ & $7.36 \pm 0.04$ & $-1.0(-2.1 / 0.0)$ & Unclear \\
\hline \multirow{2}{*}{ Base excess $(\mathrm{mmol} / \mathrm{L})$} & Pre & $4.0 \pm 2.2$ & $4.0 \pm 2.8$ & $0.0(-0.9 / 0.9)$ & Unclear \\
\hline & Post & $2.3 \pm 2.8$ & $2.5 \pm 4.9$ & $0.0(-0.9 / 1.0)$ & Unclear \\
\hline \multirow{2}{*}{ Bicarbonate (mmol/L) } & Pre & $29.5 \pm 2.1$ & $29.5 \pm 3.5$ & $0.0(-0.9 / 0.9)$ & Unclear \\
\hline & Post & $27.7 \pm 3.2$ & $27.5 \pm 4.9$ & $0.0(-1.0 / 0.9)$ & Unclear \\
\hline \multirow{2}{*}{ Lactate $(\mathrm{mmol} / \mathrm{L})$} & Pre & $1.7 \pm 0.7$ & $1.3 \pm 0.1$ & $-0.7(-1.7 / 0.2)$ & Unclear \\
\hline & Post & $2.5 \pm 0.7$ & $2.1 \pm 0.1$ & $-0.7(-1.7 / 0.2)$ & Unclear \\
\hline
\end{tabular}

Data is shown as mean \pm S.D. $*$ denotes statistical difference with the pre value $(p<0.05)$. $\alpha$ denotes statistical difference with the HH group $(p<0.05)$. $\mathrm{PCO}_{2}$ and $\mathrm{PO}_{2}=$ partial pressure of carbon dioxide and oxygen, respectively. Pre: resting condition. Post: immediately postexercise levels.

in $\mathrm{HBO}_{2}$ environment did not modify lipid peroxidation or plasma antioxidant capacity. This is in accordance with previous studies where no changes in lipid peroxidation or oxidative stress marker were reported in patients with various pathologies [37]. Moreover, Alcaraz-García et al. reported that, in professional divers, $\mathrm{HBO}_{2}$ training ( 1.7 ATA; $100 \%$ $\mathrm{O}_{2}$ ) for 2-3 times per week during 12 weeks did not induce an important oxidative hyperoxia-induced stress due an adaptive process [38]. Taken together, these data suggest that training in a $\mathrm{HBO}_{2}$ environment does not modify oxidative stress in human volunteers.

Many studies have reported an increase of antioxidant defense after $\mathrm{HBO}_{2}$ exposure $[36,37,39]$. In our study the antioxidant plasma capacity was unaffected during three weeks of $\mathrm{HBO}_{2}$ training. Possibly, intracellular changes in antioxidant defense may mediate some of our results [40]. Future studies should determine the mechanisms involved in this response to $\mathrm{HBO}_{2}$.

$\mathrm{VO}_{2}$ max is a relevant physiological variable in soccer, where significant relationships between $\mathrm{VO}_{2} \max$ and the total distance covered during games, time spent at high intensity, and team classification during tournaments had been reported [41]. It has been shown that, compared to normobaric normoxia, acute breathing of normobaric hyperoxia gas during exercise enhances performance $[13,42-$ 44]; however, chronic exercise under normobaric hyperoxia did not improve $\mathrm{VO}_{2} \max$ more than under normobaric normoxia training $[12,13,45]$. Furthermore, preexposure to $\mathrm{HBO}_{2}$ did not increase the subsequent exercise performance [11]. In the present study we show that three weeks of endurance training under $\mathrm{HBO}_{2}$ seems to induce an increase in $\mathrm{VO}_{2} \mathrm{max}$ and PPO (Figure 2). It is possible that training under $\mathrm{HBO}_{2}$ conditions increases the alveolar-capillary $\mathrm{O}_{2}$ exchange $[15,46]$. However, more studies are needed to clarify this point. Considering that training environment can affect physiological adaptations (i.e., specificity effect), it is interesting to note that although $\mathrm{VO}_{2}$ max was measured under normobaric normoxia (i.e., an environment specific to participants from the $\mathrm{NN}$ endurance training group) only soccer players who had practiced under $\mathrm{HBO}_{2}$ achieved a significant increase in this variable, highlighting the positive effect of $\mathrm{HBO}_{2}$ training on endurance performance.

The exact mechanisms involved in the increase of PPO during hyperoxia are not completely understood. However, the increased $\mathrm{VO}_{2} \max$, lower lactate, and acid-base balance under $\mathrm{HBO}_{2}$ conditions may play a significant role. In 


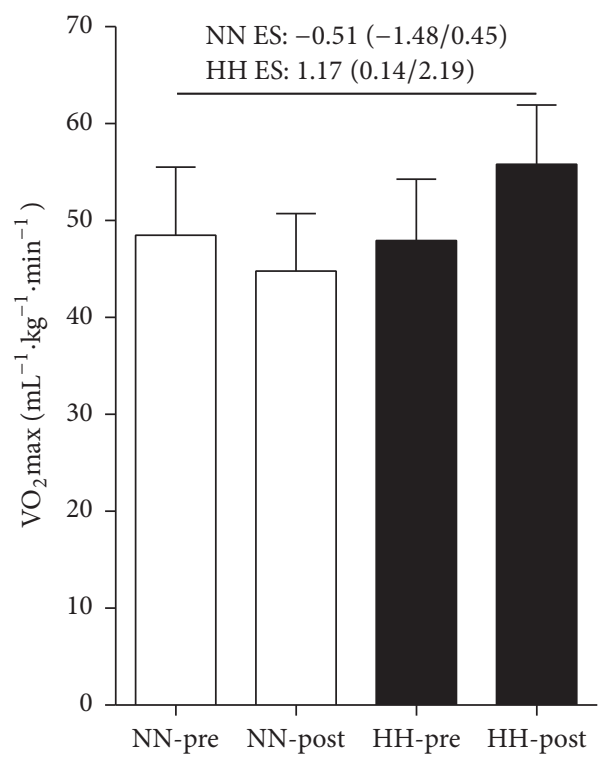

(a)

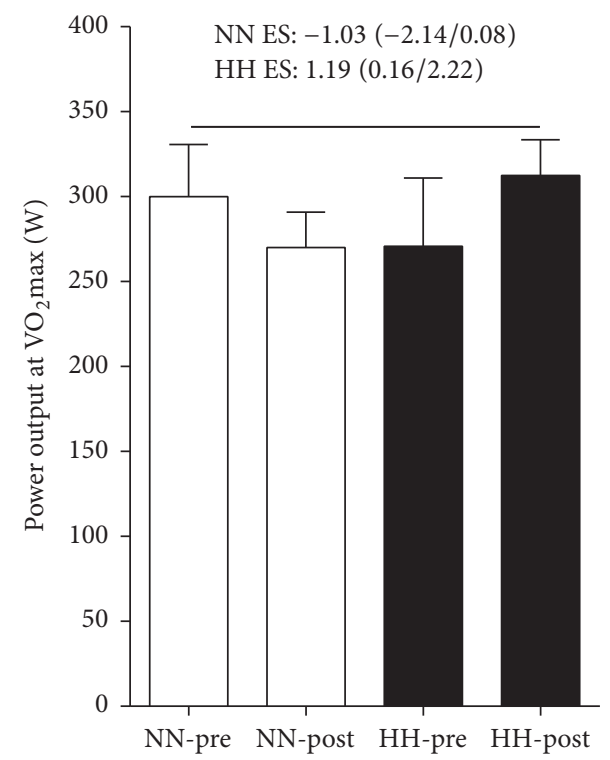

(b)

FIGURE 2: Effects of 3 weeks of $\mathrm{NN}$ and $\mathrm{HH}$ endurance training on $\mathrm{VO}_{2} \max (\mathrm{a})$ and peak power output (b) in young soccer players. ES: effect size. $\mathrm{NN}=$ normobaric normoxia; $\mathrm{HH}=$ hyperbaric hyperoxia.

this way, acute changes in plasma $\mathrm{HCO}_{3}{ }^{-}$were smaller in acute response to exercise in $\mathrm{HH}$ versus $\mathrm{NN}$, suggesting that metabolic buffering is less involved in $\mathrm{HBO}_{2}$ training. This could be related to lactate metabolism, because it has been reported that transport of lactate across the plasma membrane of skeletal muscle fibers involves a proton-linked monocarboxylate transporter, playing an important role in the $\mathrm{pH}$ regulation of skeletal muscle and extracellular fluids [47].

\section{Conclusions}

$\mathrm{HBO}_{2}$ training does not increase systemic oxidative stress markers and seems to improve endurance capacity under normobaric normoxia environment in young soccer players. Therefore, our findings warrant future investigation to corroborate that $\mathrm{HBO}_{2}$ endurance training, or other models of training as high intensity interval training and resistance training, may be an interesting training approach for highly competitive young soccer players to increase their competitive performance. Moreover, training in $\mathrm{HBO}_{2}$ conditions can be an alternative for injured athletes who need a quick return to competition.

\section{Competing Interests}

The authors declare that they have no competing interests.

\section{Acknowledgments}

This study was partially supported by the International Football Association (FIFA). The authors would like to thank all of the participants who volunteered in the study.

\section{References}

[1] P. Barata, M. Cervaens, R. Resende, Ó. Camacho, and F. Marques, "Hyperbaric oxygen effects on sports injuries," Therapeutic Advances in Musculoskeletal Disease, vol. 3, no. 2, pp. 111-121, 2011.

[2] Y. Ishii, M. Deie, N. Adachi et al., "Hyperbaric oxygen as an adjuvant for athletes," Sports Medicine, vol. 35, no. 9, pp. 739746, 2005.

[3] K. P. Stoller, "Hyperbaric oxygen therapy (1.5 ATA) in treating sports related TBI/CTE: two case reports," Medical Gas Research, vol. 1, no. 1, article 17, 2011.

[4] R. S. Richardson, "What governs skeletal muscle [latin capital $\mathrm{V}$ with dot above $\mathrm{O}_{2 \max }$ ? New evidence," Medicine \& Science in Sports \& Exercise, vol. 32, no. 1, p. 100, 2000.

[5] M. Cabric, R. Medved, P. Denoble, M. Zivkovic, and H. Kovacevic, "Effect of hyperbaric oxygenation on maximal aerobic performance in a normobaric environment," Journal of Sports Medicine and Physical Fitness, vol. 31, no. 3, pp. 362-366, 1991.

[6] G. Dennis Wilson and H. G. Welch, "Effects of hyperoxic gas mixtures on exercise tolerance in man," Medicine and Science in Sports and Exercise, vol. 7, no. 1, pp. 48-52, 1975.

[7] S. Kawada, K. Fukaya, M. Ohtani, K. Kobayashi, and C. Fukusaki, "Effects of pre-exposure to hyperbaric hyperoxia on high-intensity exercise performance," Journal of Strength and Conditioning Research, vol. 22, no. 1, pp. 66-74, 2008.

[8] B. Sperlich, T. Schiffer, S. Achtzehn, J. Mester, and H.-C. Holmberg, "Pre-exposure to hyperoxic air does not enhance power output during subsequent sprint cycling," European Journal of Applied Physiology, vol. 110, no. 2, pp. 301-305, 2010.

[9] P. Peeling and R. Andersson, "Effect of hyperoxia during the rest periods of interval training on perceptual recovery and oxygen re-saturation time," Journal of Sports Sciences, vol. 29, no. 2, pp. 147-150, 2011.

[10] A. N. H. Hodges, S. Delaney, J. M. Lecomte, V. J. Lacroix, and D. L. Montgomery, "Effect of hyperbaric oxygen on oxygen uptake 
and measurements in the blood and tissues in a normobaric environment," British Journal of Sports Medicine, vol. 37, no. 6, pp. 516-520, 2003.

[11] A. L. Webster, D. G. Syrotuik, G. J. Bell, R. L. Jones, Y. Bhambhani, and M. Young, "Exercise after acute hyperbaric oxygenation: is there an ergogenic effect?" Undersea and Hyperbaric Medicine, vol. 25, no. 3, pp. 153-159, 1998.

[12] T. Karlsen, J. Hoff, A. Støylen, M. C. Skovholdt, K. Gulbrandsen Aarhus, and J. Helgerud, "Aerobic interval training improves $\mathrm{VO}_{2 \text { peak }}$ in coronary artery disease patients; no additional effect from hyperoxia," Scandinavian Cardiovascular Journal, vol. 42, no. 5, pp. 303-309, 2008.

[13] C. G. R. Perry, J. L. Talanian, G. J. F. Heigenhauser, and L. L. Spriet, "The effects of training in hyperoxia vs. normoxia on skeletal muscle enzyme activities and exercise performance," Journal of Applied Physiology, vol. 102, no. 3, pp. 1022-1027, 2007.

[14] T. Stellingwerff, P. J. LeBlanc, M. G. Hollidge, G. J. F. Heigenhauser, and L. L. Spriet, "Hyperoxia decreases muscle glycogenolysis, lactate production, and lactate efflux during steady-state exercise," American Journal of PhysiologyEndocrinology and Metabolism, vol. 290, no. 6, pp. E1180-E1190, 2006.

[15] L. K. Weaver, S. Howe, G. L. Snow, and K. Deru, "Arterial and pulmonary arterial hemodynamics and oxygen delivery/extraction in normal humans exposed to hyperbaric air and oxygen," Journal of Applied Physiology, vol. 107, no. 1, pp. 336345, 2009.

[16] J. W. Calvert, C. Zhou, A. Nanda, and J. H. Zhang, "Effect of hyperbaric oxygen on apoptosis in neonatal hypoxia-ischemia rat model," Journal of Applied Physiology, vol. 95, no. 5, pp. 20722080, 2003.

[17] T. Matsunami, Y. Sato, Y. Hasegawa et al., "Enhancement of reactive oxygen species and induction of apoptosis in streptozotocin-induced diabetic rats under hyperbaric oxygen exposure," International Journal of Clinical and Experimental Pathology, vol. 4, no. 3, pp. 255-266, 2011.

[18] A. Rothfuss, O. Merk, P. Radermacher, and G. Speit, "Evaluation of mutagenic effects of hyperbaric oxygen (HBO) in vitro. II. Induction of oxidative DNA damage and mutations in the mouse lymphoma assay," Mutation Research/Genetic Toxicology and Environmental Mutagenesis, vol. 471, no. 1-2, pp. 87-94, 2000.

[19] R. Arieli, Y. Arieli, Y. Daskalovic, M. Eynan, and A. Abramovich, "CNS oxygen toxicity in closed-circuit diving: signs and symptoms before loss of consciousness," Aviation Space and Environmental Medicine, vol. 77, no. 11, pp. 1153-1157, 2006.

[20] R. Arieli, T. Shochat, and Y. Adir, "CNS toxicity in closed-circuit oxygen diving: symptoms reported from 2527 dives," Aviation Space and Environmental Medicine, vol. 77, no. 5, pp. 526-532, 2006.

[21] C. M. Muth, Y. Glenz, M. Klaus, P. Radermacher, G. Speit, and $\mathrm{X}$. Leverve, "Influence of an orally effective SOD on hyperbaric oxygen-related cell damage," Free Radical Research, vol. 38, no. 9, pp. 927-932, 2004.

[22] M. Amann, A. Subudhi, and C. Foster, "Influence of testing protocol on ventilatory thresholds and cycling performance," Medicine and Science in Sports and Exercise, vol. 36, no. 4, pp. 613-622, 2004.

[23] E. T. Howley, D. R. Bassett, and H. G. Welch, "Criteria for maximal oxygen uptake: review and commentary," Medicine and Science in Sports and Exercise, vol. 27, no. 9, pp. 1292-1301, 1995.
[24] J. Nouroozzadeh, J. Tajaddinisarmadi, and S. P. Wolff, "Measurement of plasma hydroperoxide concentrations by the ferrous oxidation-xylenol orange assay in conjunction with triphenylphosphine," Analytical Biochemistry, vol. 220, no. 2, pp. 403-409, 1994

[25] E. A. Lissi, M. Salim-Hanna, T. Sir, and L. A. Videla, "Is spontaneous urinary visible chemiluminescence a reflection of in vivo oxidative stress?" Free Radical Biology and Medicine, vol. 12, no. 4, pp. 317-322, 1992.

[26] E. Lissi, C. Pascual, and M. D. Del Castillo, "Luminol luminescence induced by 2,2'-azo-bis(2-amidinopropane) thermolysis," Free Radical Research, vol. 17, no. 5, pp. 299-311, 1992.

[27] S. Ückert and W. Joch, "Effects of warm-up and precooling on endurance performance in the heat," British Journal of Sports Medicine, vol. 41, no. 6, pp. 380-384, 2007.

[28] F. M. Impellizzeri, S. M. Marcora, C. Castagna et al., "Physiological and performance effects of generic versus specific aerobic training in soccer players," International Journal of Sports Medicine, vol. 27, no. 6, pp. 483-492, 2006.

[29] T. Saanijoki, L. Nummenmaa, J.-J. Eskelinen et al., "Affective responses to repeated sessions of high-intensity interval training," Medicine \& Science in Sports \& Exercise, vol. 47, no. 12, pp. 2604-2611, 2015.

[30] D. Lakens, "Calculating and reporting effect sizes to facilitate cumulative science: a practical primer for t-tests and ANOVAs," Frontiers in Psychology, vol. 4, article 863, 2013.

[31] J. Stanley, A. Halliday, S. D'Auria, M. Buchheit, and A. S. Leicht, "Effect of sauna-based heat acclimation on plasma volume and heart rate variability," European Journal of Applied Physiology, vol. 115, no. 4, pp. 785-794, 2015.

[32] C. Henríquez-Olguín, A. Díaz-Vegas, Y. Utreras-Mendoza et al., "NOX2 inhibition impairs early muscle gene expression induced by a single exercise bout," Frontiers in Physiology, vol. 7, article no. 282, 2016.

[33] A. Hernández, A. Cheng, and H. Westerblad, "Antioxidants and skeletal muscle performance: "Common knowledge" vs. experimental evidence," Frontiers in Physiology, vol. 3, article 46, 2012.

[34] A. J. Braakhuis and W. G. Hopkins, "Impact of dietary antioxidants on sport performance: a review," Sports Medicine, vol. 45, no. 7, pp. 939-955, 2015.

[35] B. J. Ganguly, N. Tonomura, R. M. Benson, B. A. Osborne, and E. V. Granowitz, "Hyperbaric oxygen enhances apoptosis in hematopoietic cells," Apoptosis, vol. 7, no. 6, pp. 499-510, 2002.

[36] C. Dennog, A. Hartmann, G. Frey, and G. Speit, "Detection of DNA damage after hyperbaric oxygen (HBO) therapy," Mutagenesis, vol. 11, no. 6, pp. 605-609, 1996.

[37] A. Eken, A. Aydin, A. Sayal, A. Üstündağ, Y. Duydu, and K. Dündar, "The effects of hyperbaric oxygen treatment on oxidative stress and SCE frequencies in humans," Clinical Biochemistry, vol. 38, no. 12, pp. 1133-1137, 2005.

[38] M. J. Alcaraz-García, M. D. Albaladejo, C. Acevedo et al., "Effects of hyperoxia on biomarkers of oxidative stress in closed-circuit oxygen military divers," Journal of Physiology and Biochemistry, vol. 64, no. 2, pp. 135-142, 2008.

[39] F. Gürdöl, M. Cimşit, Y. Öner-Iyidoğan, Körpinar, S. Yalçinkaya, and H. Koçak, "Early and late effects of hyperbaric oxygen treatment on oxidative stress parameters in diabetic patients," Physiological Research, vol. 57, no. 1, pp. 41-47, 2008.

[40] Z. Radak, H. Y. Chung, E. Koltai, A. W. Taylor, and S. Goto, "Exercise, oxidative stress and hormesis," Ageing Research Reviews, vol. 7, no. 1, pp. 34-42, 2008. 
[41] F. M. Impellizzeri, E. Rampinini, and S. M. Marcora, "Physiological assessment of aerobic training in soccer," Journal of Sports Sciences, vol. 23, no. 6, pp. 583-592, 2005.

[42] R. P. Adams and H. G. Welch, "Oxygen uptake, acid-base status, and performance with varied inspired oxygen fractions," Journal of Applied Physiology Respiratory Environmental and Exercise Physiology, vol. 49, no. 5, pp. 863-868, 1980.

[43] M. C. Hogan, R. H. Cox, and H. G. Welch, "Lactate accumulation during incremental exercise with varied inspired oxygen fractions," Journal of Applied Physiology Respiratory Environmental and Exercise Physiology, vol. 55, no. 4, pp. 11341140, 1983.

[44] J. Plet, P. K. Pedersen, F. B. Jensen, and J. K. Hansen, "Increased working capacity with hyperoxia in humans," European Journal of Applied Physiology and Occupational Physiology, vol. 65, no. 2, pp. 171-177, 1992.

[45] C. G. R. Perry, J. Reid, W. Perry, and B. A. Wilson, "Effects of hyperoxic training on performance and cardiorespiratory response to exercise," Medicine \& Science in Sports \& Exercise, vol. 37, no. 7, pp. 1175-1179, 2005.

[46] D. P. Casey, M. J. Joyner, P. L. Claus, and T. B. Curry, "Hyperbaric hyperoxia reduces exercising forearm blood flow in humans," American Journal of Physiology-Heart and Circulatory Physiology, vol. 300, no. 5, pp. H1892-H1897, 2011.

[47] G. Juel and A. P. Halestrap, "Lactate transport in skeletal muscle-role and regulation of the monocarboxylate transporter," Journal of Physiology, vol. 517, no. 3, pp. 633-642, 1999. 


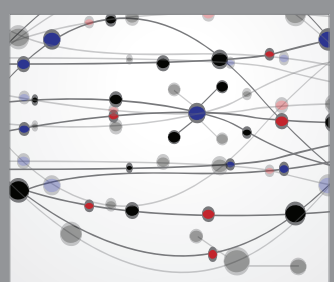

The Scientific World Journal
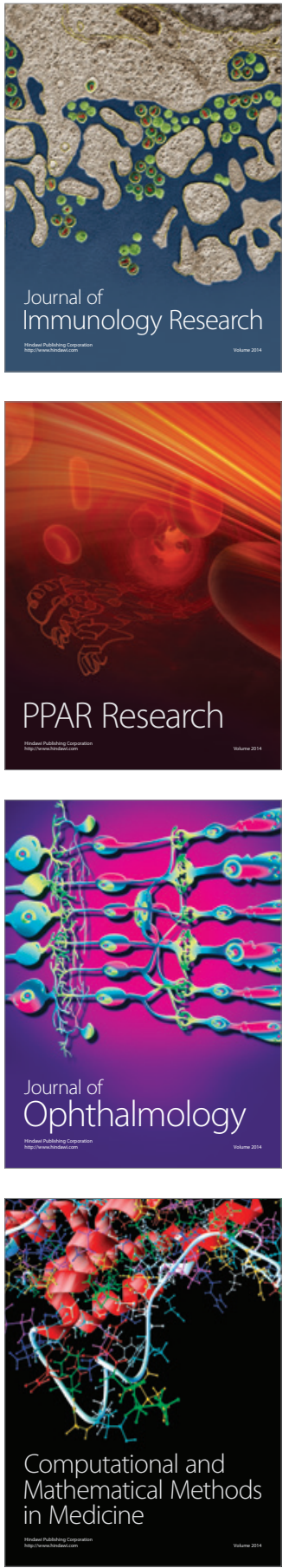

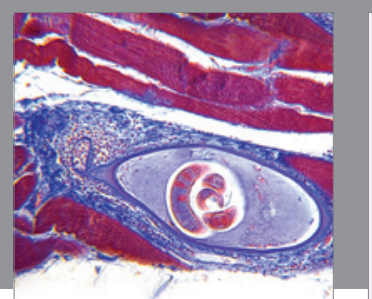

Gastroenterology Research and Practice

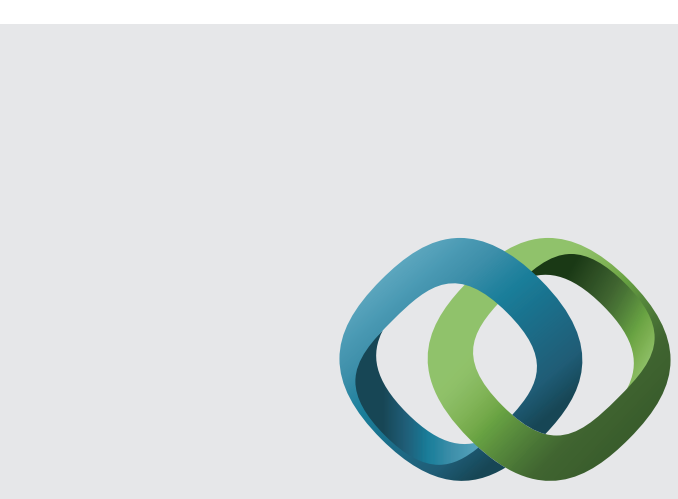

\section{Hindawi}

Submit your manuscripts at

http://www.hindawi.com
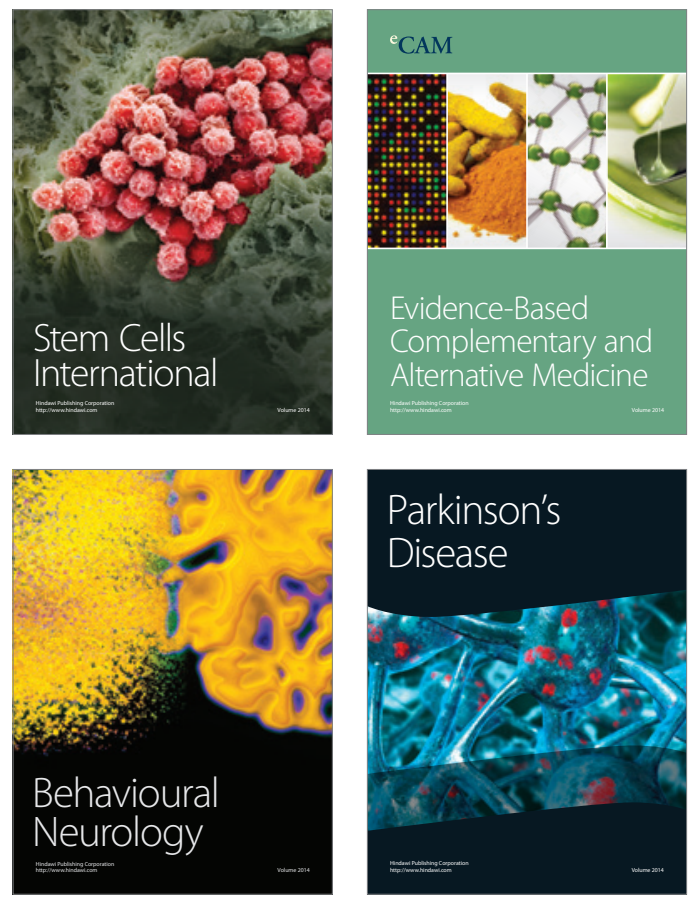
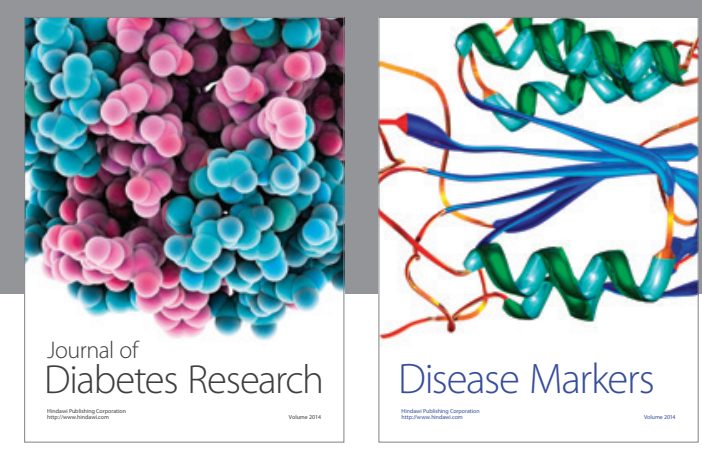

Disease Markers
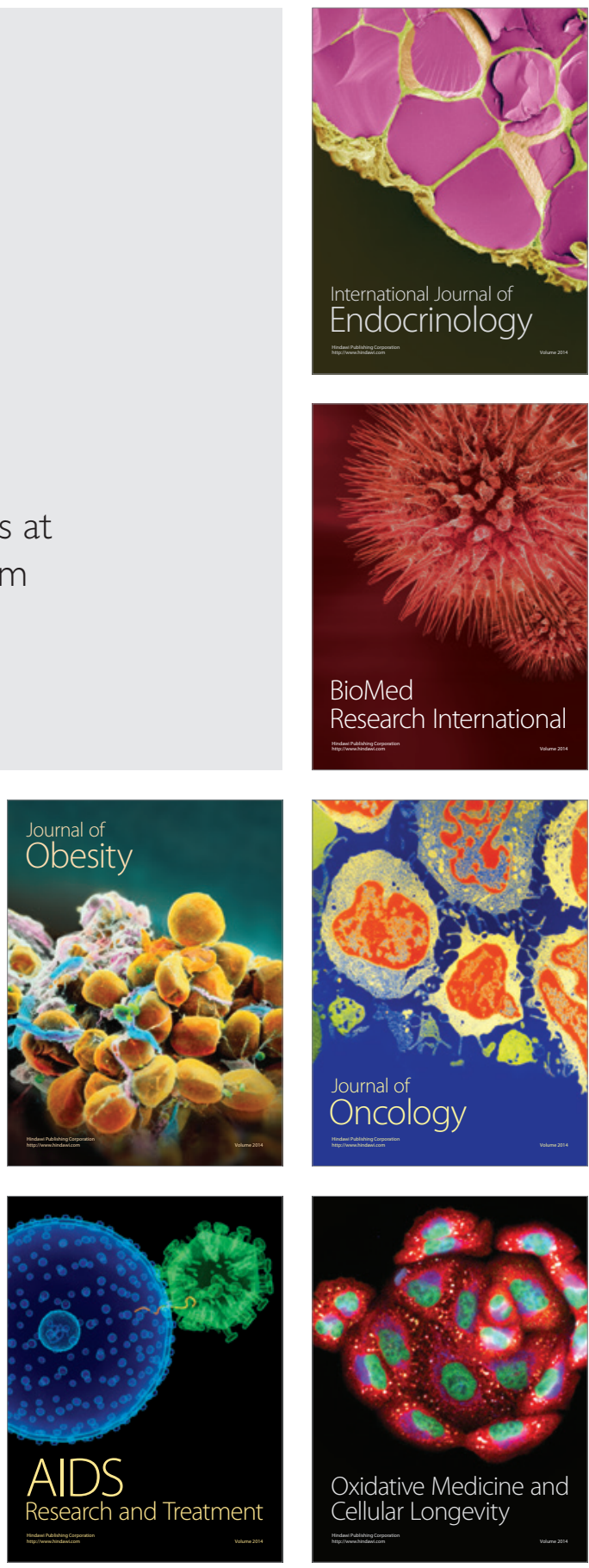